\title{
USE OF BIG DATA AND AI TOOLS TO EVALUATE AND ASSIST STARTUPS
}

\author{
Athanasios Davalas
}

Aegean University

DOI: 10.46609/IJSSER.2020.v05i11.019 URL: https://doi.org/10.46609/IJSSER.2020.v05i11.019

\begin{abstract}
Startup businesses are striving from the very beginning to understand their customers' needs and gain competitive advantage over their competitors. As they are running out of budget, time and other resources sooner than corporates they need to rely to disrupting technologies such as Artificial Intelligence (AI) and Big Data to progress to a next round. In this report, we present those dimensions of these technologies which empower startups on understanding and modelling customers' behavior and customers' needs. These are presented from the point of view of prospects and challenges considering, in one hand, the benefits of bringing data analytics into production or service delivery, but also considering the challenges for the startups to prove that they can deliver the right products or services. The confluence of the AI and Big Data technologies transcends all the sectors of even a startup business (manufacturing, information technology, finance, technical operations, customer services, logistics, etc). However, the challenge of a startup is to harvest the best possible business intelligence and implement targeted and earlier innovations.
\end{abstract}

\section{Introduction}

Today businesses are striving to stay competitive in a dynamic marketplace. For a startup business to be established and remain relevant in the market, it requires unconventional wisdom of production, marketing as well as knowing and retaining its customers. Startups in most of the occasions tend to struggle with budget issues when it comes to production and marketing, as well as need to ensure that they have established potentially high consumer conversion rate.

Indeed, one of the critical elements that can be used to differentiate startups is the pace (Obschonka\&Audretsch, 2019). What technologies startup companies need to be able to establish business at the first-rate to ensure that are able to compete with big companies? Has the technology those capabilities which are necessary to model customers' behavior and customers' 
International Journal of Social Science and Economic Research

ISSN: 2455-8834

Volume:05, Issue:11 "November 2020"

needs? Can startups can make efficient use of these technologies to develop the right products for the right needs?.

More and more researchers claim that to be able to react to ever-changing market conditions, startups need to rely heavily on artificial intelligence (AI) and Big Data analytics (Saura et al., 2019).In this context, the objective of this report is to outline how startup businesses can use various AI and Big Data tools to establish themselves and survive in the marketplace. AI and Big Data capabilities provide to an entrepreneur those tools and techniques that will allow them to obtain insights on consumers' behavior. Having this knowledge as core, the technology can then help startups in marketing, operations, customer services, advertising, and inventory management.

In the rest of the report, we are presenting how AI and Big Daa contribute to the marketing and the business development operations of the startups to achieve growth and establishment of brand value. AI and Big Data can help the business identify and reach out to the right market to launch their products and achievea desirable marketing return (Chen et al., 2012).

\section{How AI and Big Data Tools Can Assist Startups}

There are various ways in which startups can leverage AI and Big Data tools. The following elements outline the possible ways that the startups will benefit from the technology.

\section{Tracking Potential Customers}

With the help of AI and Big Data analytics, startups business can gain an entire picture of their potential customers and it can be used in predicting customer behavioral patterns (Bredt, 2019). For instance, if a startup needs to find the target market through the use of AI, the technology will compile market analysis reports, competitor analysis, and social feedback, among other data sources. The correlation of various data obtained can lead to identifying and understanding requirements on the target market (Obschonka\&Audretsch, 2019). At a next stage, the startup can use this information in two main directions:

a. Achieve product design including innovative and new features which match to the needs of the target market in shorter time.

b. Optimisethe market development process for reaching new customer base for new products as well as make them reachable by the existing customers.

In the marketplace, customer buying patterns tend to be affected by various factors. Some of them include price, brand popularity, offers, experience, and more. With the help of Big Data 
International Journal of Social Science and Economic Research

ISSN: 2455-8834

Volume:05, Issue:11 "November 2020"

and AI tools, startups proceed to processing and generating complex analysis reports about customers (Obschonka\&Audretsch, 2019). Based on such trend analysis report and predictive analytics the company may develop a wide range of products that meets market demand.

Moreover the startup transforms the context and the time it decides to interact with a potential customer. Engaging customers (directly or indirectly) helps in gaining market feedback, which can be transformed into offering improved or enhanced services.

\section{Facebook Analytics for the Startups}

The most common AI and Big Data analytic tool that can be embraced by the startup is Facebook analytics. Nowadays, the tool is popular to the startups because it provides a multichannel analytics platform. An entrepreneur can gain insights on how and where people best interact with business across mobile applications, websites, Facebook pages, and many more. Identification of the most frequent channel used by the target customers can be used to optimize the growth of the startup . More efficient marketing strategies are likely to be generated based on the Facebook analytics for the main reason that target customers can be mined considering the channel they are using (Lin et al., 2016). In a nutshell, Facebook analytics is an influencing tool for startups because it provides insights from an online community of two billion-person people .

Anonymous, aggregated data tend to outline a comprehensive picture of the possible customers that may be interested in the product or the service to be developed (Lin et al., 2016). As illustrated in the below figure, Facebook analytics is a vital AI tool for the startup because it helps in formulating the profile of the target market with multiple dimensions. Consumers' behavior, geography as well as demographics features of the target customers, are some of these dimensions which provide valuable insights for the business. 
International Journal of Social Science and Economic Research

ISSN: 2455-8834

Volume:05, Issue:11 "November 2020"

Figure 1: Using Facebook analytics to find a promising business location Source:(Lin et al., 2016)
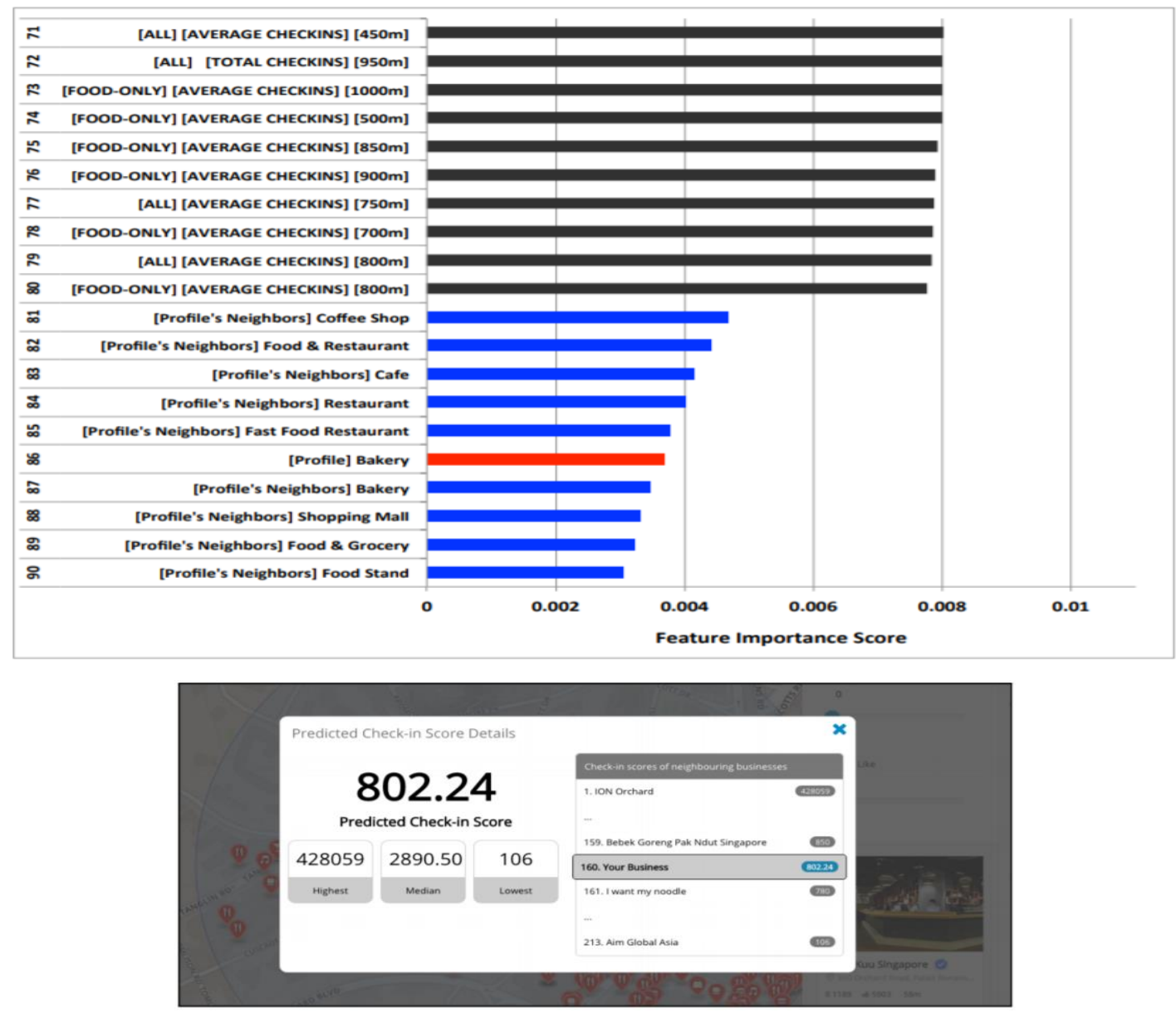

\section{Increasing Productivity}

Most of the startups tend to run various business operations on a limited budget. The company tends to expect maximum value from the resources invested in starting the venture. AI and Big Data tools contribute to relevant decision making following an 'Experiment-Fail-Learn-Repeat' approach. Through this approach, the business tests first if its operations will be viable in the marketplace.

Embracing AI and Big Data helps in providing the startup with enterprise-grade experience (Chen et al., 2012). The experience is manifested through unlimited scalability, and anywhere accessibility backed with reliable information technology infrastructure. 


\section{International Journal of Social Science and Economic Research}

ISSN: $2455-8834$

Volume:05, Issue:11 "November 2020"

The use of technology contributes to the reduction of advertising or marketing expenses. Minimization of the liabilities implies that the production cost is efficiently managed. Enterpriseexperience helps a startup to become more agile, and address any prevailing conditions in the dynamic marketplace (Obschonka\&Audretsch, 2019).

Proper understanding leads to the right reaction by the startup hence enhancing its viability. For instance, if a startup proceeds toa product launch, the business can set up cloud-based infrastructures. When AI ad Big Data technologies are added to the support, a massive amount of real-time information can be churned out from medial social data, among other sources(Bredt, 2019). The startup, therefore, can use technology of limited capex to ensure that it increases its market share faster than an established business in order to survive.

Also, AI and Big Data tools are increasingly being used for the optimization of various business operations. Now days, the business processes of startups are generating massive amount of real time data. These data are valuable repository of knowledge regarding process optimisation decisions (Bredt, 2019). For example, data from sensors on delivery vehicles can be examined through AI tools to generate ways that efficiency can be fostered.

All the possible tools utilized by the startup business can be intelligence- empowered implying that they are connected and data-enabled to allow regular data sharing to one another (Saura et al., 2019). Through analysis of the data provided by the intelligent tools, the company will be able to gain real-time operational visibility. Operational visibility, therefore, can be used in the creation of possible ways that efficiency can be increased.

Also, startups in retail business can utilize AI and Big Data in optimizing stock-keeping based on data generated from various sources. Data used in this case can be retrieved from social media, weather forecast as well as web search to predict the minimum stock required to support sales. And vice versa, they want to reduce unwanted inventory (Hilbig et al., 2018).

Startup businesses can benefit from Big Data and AI in its supply chain as well. AI sensors can be integrated into supply vehicles contributing to their efficient tracking and delivery scheduling (Obschonka\&Audretsch, 2019). For example, the route used during product supply can be optimized through integration with live traffic information. Therefore, there are various means that AI and Big Data tools can be deployed in startup business to efficiency hence productivity.

\section{Strategic Growth}

AI and Big Data help to predict and identify accurate behavioral patterns. Marketing or advertising has to be based on data insights to ensure that efficiency is reached (Garbuio\& Lin, 


\section{International Journal of Social Science and Economic Research}

ISSN: $2455-8834$

Volume:05, Issue:11 "November 2020"

2019)and define the right directions for the business. This can be in multiple forms including the following:

- calculate the maximum probability of meeting any specific business goals.

- Define strategic and operational goals which are realistically linked to the startup's vision and mission.

- Support rapid what-if scenarios in helping the business to examine all the possible directions to follow (Chen et al., 2012).

- Calculate market size based on data acquired from multiple sourcesand the maximum chance of achieving a particular marketplace can be deduced.

\section{Checking Out the Competition}

As one main method of the past to understand competition, the companies had to visit rival shops and websitesas if they were true customers. In the current marketplace, it is very convenient and easy for a person to find out relevant information about a competitor in the market. Financial data about the industry tends to be readily available, or Big Data tools, for instance, Google Barometer can be utilized in offering information regarding how the target customers use internet (Obschonka\&Audretsch, 2019).

Moreover, the frequency that a particular company is referencedto potential customers' interactions on social mediais mined using such tools. Data about the viability of an industry can also be extracted through various Big Data tools to perform rapid analysis about the industry competition (Mitomo, 2017).

As illustrated in the following figure, Google Barometer makes available insights about customers' behavior in few clicks and determineseasily the success criteria of alternative business campaigns, for example:

- Does the company have the minimum required market segment to survive?

- Does it even have more room to grow more in the market (Bredt, 2019)?

- What do we know about the profitability of other competitors(Saura et al., 2019)?

Gaining critical insights about competitors as those mentioned above can be used by the business into formulating feasible strategies against competition. 
International Journal of Social Science and Economic Research

ISSN: 2455-8834

Volume:05, Issue:11 "November 2020"

Figure 2: How to Use Google Barometer Source: (Saura et al., 2019)

\begin{tabular}{|c|c|c|c|c|}
\hline \multicolumn{2}{|c|}{ Consumer Barometer with Google } & \multirow{2}{*}{$\begin{array}{l}\text { Graph Builder Trended Data Audience Stories Curated Insights } \\
\text { The Online } 8 \text { Multiscreen Wortd - } 3 \text { of } 19\end{array}$} & \multicolumn{2}{|c|}{ Help About } \\
\hline Questrons & futens & & $\langle>$ & $\vdots$ \\
\hline The Online \& Muttiscreen World & & us $\mathrm{x}$ & & \\
\hline Internet Usage & 2 & & & \\
\hline Internet User Segmentation & ^ & How digitally-savvy are people? & & \\
\hline Digital Savy & & Ioften post content ontine & Hid & \\
\hline Device usage & 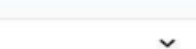 & Ioften show other people how to do things online & & \\
\hline TV 8 Connected Devices & $\sim$ & $38 \mathrm{x}$ & & \\
\hline The Smart Shopper & & When I need intormation, the frst place llook is the Intermet & Hid & \\
\hline & & 728 & & \\
\hline First Awareness & $\sim$ & Using the Interent is fun to me & Hid & \\
\hline Research Behavior & $\checkmark$ & 608 & & \\
\hline Purchase Behavior & $\checkmark$ & If have the opportunity to do a task digtally, I prefer doing it that way & Hid & \\
\hline Searching for Local Intormation & $\checkmark$ & 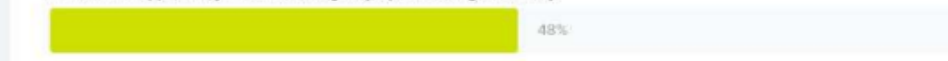 & & \\
\hline International Purchases & $\sim$ & & & \\
\hline The Smart Viewer & & 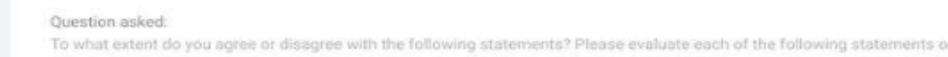 & on acosite & \\
\hline
\end{tabular}

\section{Recruiting and Managing Talent}

Startup business, in most cases, always required skilled labor in various functions to ensure that desired objectives are met. The company should able to seek and acquire the right candidates at the right time based on internally generated reports. Big Data and AI tools collect relevant information to be used for new recruitments (Garbuio\&Lin, 2019). Human resource-related data can be generated on-demand extracting them from productivity data, staff satisfaction reviews, absenteeism figures, future development needs. Big Data and AI tools can be used in ensuring that startup business maintains and acquires the right candidates who are able to enhance the company vision.

\section{How a Startup Can Harness the Power of AI and Big Data}

$\mathrm{AI}$ and Big Data markets are vast, and more companies are investing in their capabilities. The information provided by theses technological tools ten to be enormous; therefore it is very 


\section{International Journal of Social Science and Economic Research}

ISSN: $2455-8834$

Volume:05, Issue:11 "November 2020"

critical for a startup to establish where to begin. Before a startup is ready to implement and use Big Data as well as AI tools, it is necessary to consider the below elements:

1. Experienced Big-Data team: - A startup needs to have a team of experts in strategy, data collection, and analytics. The team will help in the creation of an AI approach that is well-aligned to the business objectives. The group established by the company needs to entail people with a better understanding of modern analytics methods (Reim et al., 2020). Knowledge of advanced analytics will help in the proper analysis of various data sets. Skilled and knowledgeable consultants are as well required to ensure that overarching business objectives are well understood and structured based on insights gained from AI and Big Data tools.

2. Identify end goals: - The right objectives need to be structured, which is very vital in the implementation of AI and Big Data solutions. Operation or use of AI ad Big Data tools needs to be aligned to the startup company's end goals.

3. Capture the right data: -After outlining the end goal for the business, data acquired from AI and Big Data need to be fully comprehended. Capturing, identification as well as tracking of relevant information needs to be set as the backbone of all AI and Big Data processes (Lee et al., 2019). The use of wrong data may result in catastrophic consequences to the startup business.

4. Apply proper analytic methods: - Proper technique is required to ensure that information gathered by AI and Big Data tools is translated into relevant insights.

\section{Conclusion}

Startups need to adopt emerging business innovations at the first-rate to ensure that are able to compete with big companies. AI and Big Data are very crucial weapons to their strategy helping the businesses identify and reach out to the right market for faster product launching and market return. Startups need to take maximum benefit of the technological capabilities to understand customers' needs. This analysis will entail the development of competitive and innovative products. Moreover, embracing AI and Big Data help in providing the startup with enterprisegrade experience. The experience is manifested through unlimited scalability, and anywhere accessibility backed with reliable information technology infrastructure. Utilizing Big Data and AI can provide useful information that can be used but the company to examine the possible direction to take. 
International Journal of Social Science and Economic Research

ISSN: 2455-8834

Volume:05, Issue:11 "November 2020"

\section{References}

Bredt, S. (2019). Artificial Intelligence (AI) in the Financial Sector-Potential and Public Strategies. Frontiers in Artificial Intelligence, 2, 16. https://www.frontiersin.org/articles/10.3389/frai.2019.00016/full?utm_source=STWT\&utm_medium=SNET\&utm_campaign=ECO_FRAI_FDATA_XXXXXXXX_auto-dlvrit

Chen, H., Chiang, R. H., \& Storey, V. C. (2012). Business intelligence and analytics: From big data to big impact. MIS quarterly, 1165-1188. https://pdfs.semanticscholar.org/f5fe/b79e04b2e7b61d17a6df79a44faf358e60cd.pdf\%3E.

Garbuio, M., \& Lin, N. (2019). Artificial intelligence as a growth engine for health care startup: emerging business models. California Management Review, 61(2), 59-83.

https://pdfs.semanticscholar.org/78ce/7d0cfecf37c0e079afb4150b097e11c61109.pdf

Hilbig, R., Etsiwah, B., \& Hecht, S. (2018, December). Berlin Start-ups-The Rise of DataDriven Business Models. In ISPIM Innovation Symposium (pp. 1-19). The International Society for Professional Innovation Management (ISPIM).

https://www.researchgate.net/profile/Romy_Hilbig/publication/329529109_Berlin_Start-ups__The_Rise_of_Data-Driven_Business_Models/links/5c0e43f34585157ac1b73648/Berlin-Startups-The-Rise-of-Data-Driven-Business-Models.pdf

Lee, J., Suh, T., Roy, D., \& Baucus, M. (2019). Emerging technology and business model innovation: the case of artificial intelligence. Journal of Open Innovation: Technology, Market, and Complexity, 5(3), 44. https://www.mdpi.com/2199-8531/5/3/44/pdf

Lin, J., Oentaryo, R., Lim, E. P., Vu, C., Vu, A., \&Kwee, A. (2016, July). Where is the goldmine? Finding promising business locations through Facebook data analytics.

In Proceedings of the 27th ACM Conference on Hypertext and Social Media (pp. 93-102). https://arxiv.org/pdf/1609.02839

Mitomo, H. (2017). Data network effects: Implications for data business. https://www.econstor.eu/bitstream/10419/169484/1/Mitomo.pdf

Nick, C. (2019). How to Use Google Trends for Keyword Research: 7 Effective Ways. https://ahrefs.com/blog/how-to-use-google-trends-for-keyword-research/

Obschonka, M., \&Audretsch, D. B. (2019). Artificial intelligence and big data in entrepreneurship: a new era has begun. Small Business Economics, 1-11. https://arxiv.org/pdf/1906.00553 
Reim, W., Åström, J., \& Eriksson, O. (2020). Implementation of Artificial Intelligence (AI): A Roadmap for Business Model Innovation. AI, 1(2), 180-191. https://www.mdpi.com/26732688/1/2/11/pdf

Saura, J. R., Palos-Sanchez, P., \&Grilo, A. (2019). Detecting indicators for startup business success: Sentiment analysis using text data mining. Sustainability, 11(3), 917. https://www.mdpi.com/2071-105 